\title{
Genuine traditional Korean medicine, BaekJeol-Tang for the treatment of rheumatoid arthritis
}

Na-Ra Han ${ }^{1, *}$,Woo-Moon Sim ${ }^{2}$, Moo-Chang Sul ${ }^{2}$, Min-Cheol Kim ${ }^{3}$, Chang-Hee Lee ${ }^{4}$, Dong- Won Kim ${ }^{5}$, Se-Hun Lee ${ }^{6}$, Ho-Cheol Lee ${ }^{7}$, Jong-Min Ryu ${ }^{8}$, Bong-Soo Nam ${ }^{9}$, Jong-Ok Kim ${ }^{10}$, Seong-Oh Moon ${ }^{11}$, Hyeon-Lok Jang ${ }^{12}$, Young-Seok $\mathrm{Kim}^{13}$, Ihn Lee ${ }^{14}$, Jin-Young Yang ${ }^{15}$, Kyu-Sun Hwang ${ }^{16}$, Chang-Sun Chun ${ }^{17}$, Hyeon-Seok Jeong ${ }^{18}$

${ }^{l}$ Department of Pharmacology, College of Korean Medicine, Kyung Hee University, Dongdaemun-gu, Seoul; ${ }^{2}$ TeunTeunMadi Korean Medical Clinic, Gangnam-gu, Seoul; ${ }^{3}$ TeunTeunMadi Korean Medical Clinic, Mok-dong, Seoul; ${ }^{4}$ TeunTeunMadi Korean Medical Clinic, Nowon-gu, Seoul; ${ }^{5}$ TeunTeunMadi Korean Medical Clinic, Mapo-gu, Seoul; ${ }^{6}$ TeunTeunMadi Korean Medical Clinic, Cheonan; ${ }^{7}$ TeunTeunMadi Korean Medical Clinic, Seomyeon, Busan; ${ }^{8}$ TeunTeunMadi Korean Medical Clinic, Incheon; ${ }^{9}$ TeunTeunMadi Korean Medical Clinic, Anyang; ${ }^{10}$ TeunTeunMadi Korean Medical Clinic, Suwon; ${ }^{11}$ TeunTeunMadi Korean Medical Clinic, Daegu; ${ }^{12}$ TeunTeunMadi Korean Medical Clinic, Bundang; ${ }^{13}$ TeunTeunMadi Korean Medical Clinic, Gwangju; ${ }^{14}$ TeunTeunMadi Korean Medical Clinic, Ilsan; ${ }^{15}$ TeunTeunMadi Korean Medical Clinic, Daejeon; ${ }^{16}$ TeunTeunMadi Korean Medical Clinic, Bucheon;

${ }^{17}$ Yaksan Korean Medical Clinic; ${ }^{18}$ Barokeo Korean Medical Clinic, Republic of Korea

\begin{abstract}
Inflammation in rheumatoid arthritis is characterized by immune cell infiltration and cytokine secretion. In particular, mast cells and their cytokines play an important role in the pathogenesis of rheumatoid arthritis. Korean medicine, BaekJeol-Tang (BT) was designed by traditional Korean medicine theory. We already reported therapeutic effect of BT in rheumatoid arthritis. Here, we report the specific underlying mechanism of BT in activated human mast cells, HMC-1 cells. In addition, we report for the first time that BT significantly inhibited the production and mRNA expression of proinflammatory cytokines including thymic stromal lymphopoietin, interleukin (IL)-1 $\beta$, IL-6, IL-8, and tumor necrosis factor- $\alpha$ in activated HMC-1 cells. BT also decreased the activation of mitogen-activated protein kinases, nuclear factor- $\mathrm{\kappa B}$, and caspapase-1. Taken together, these results indicate that BT has potential as a regulator of inflammatory reactions for the treatment of arthritis such as osteoarthritis and rheumatoid arthritis.
\end{abstract}

Keywords rheumatoid arthritis, BaekJeol-Tang, mast cells, caspase-1, thymic stromal lymphopoietin, ostheoarthritis

\section{INTRODUCTION}

Rheumatoid arthritis (RA) induces inflammatory and destructive processes in synovium, cartilage, bone, and bone marrow (Schett and Firestein, 2010). Osteoarthritis (OA) is primarily described as a disease of cartilage damage (Clockaerts et al., 2011). The disease process in both OA and RA is influenced by systemic and metabolic disturbances and inflammatory processes (van Eekeren et al., 2013). Inflammation in OA and RA is characterized by immune cell infiltration (de Lange-Brokaar et al., 2012). Most frequently found cells types were macrophages, $T$ cells, and mast cells. In particular, mast cells and their cytokines play an important role in the pathogenesis of rheumatoid arthritis (Bridges et al., 1991; Cauli et al., 2000; Dean et al., 1993). Overall mast cell numbers in RA and OA patients were higher than in normal controls (Buckley et al., 1998; Dean et al., 1993; Ceponis et al., 1998). The mast cells were mainly found within the sublining layer and around blood vessels (Damsgaard et al., 1999). The number of degranulated mast cells was highest in superficial layers of OA synovial tissues. However, the number of mast cells in RA synovial tissues was increased in the capsule (Dean

\footnotetext{
*Correspondence: Na-Ra Han

E-mail: nrhan@khu.ac.kr

Received April 25, 2013; Accepted May 13, 2013; Published May 31, 2013

doi: http://dx.doi.org/10.5667/tang.2013.0010

(C)2013 by Association of Humanitas Medicine

TANG / www.e-tang.org
}

et al., 1993). Inflammation is also characterized by inflammatory cytokine secretion in OA and RA (de Lange-Brokaar et al., 2012). Interleukin (IL)-1 $\beta$ and tumor necrosis factor alpha (TNF- $\alpha$ ) are proinflammatory cytokines and increase the inflammatory reactions. These cytokines were seen in lining layer and sublining layer (Melchiorri et al., 1998). Moreover, IL-1 $\beta$ was induced by IL-1 $\beta$-converting enzyme (ICE, caspase-1) in OA synovial tissues (Saha et al., 1999). IL-6 was detected in lining layer of OA synovial tissues (de Lange-Brokaar et al., 2012; Doss et al., 2007). Another cytokine associated with innate immunity, IL-8 was produced in the synovial membrane, cartilage-pannus junction, and chondrocytes and detected in deeper layers and around vessels (Deleuran et al., 1994). Thymic stromal lymphopoietin (TSLP) plays a pivotal role not only in allergic diseases but also in inflammatory arthritis (Koyama et al., 2007). These cytokines are expressed in mast cells via the mitogen activated protein kinase (MAPKs)/nuclear factor (NF)- $\kappa \mathrm{B} /$ caspase-1 signaling pathways (Zhang et al., 2007; Moon et al., 2011).

Traditional Korean medicine, BaekJeol-Tang (BT) has been used to treat rheumatoid arthritis and to protect injured chondrocytes in Korean medical clinic. BT is composed of shark cartilage, Atractylodis Rhizoma (蒼术), Phellodendri Cortex (黃柏), and Sophora Radix (苦落). The traditional Korean medicine describes that the pathological dampness-heat in body can induce articular pain, swelling, carbuncle, or furuncle (Heo, 1999), etc. Clear heat and dry dampness medicinal (清熱燥濕藥) have been mostly used at treatment

2013 / Volume 3 / Issue 2 / e18 
for these diseases. Phellodendri Cortex keeps cold character and has been used to treat arthralgia or knee pain (Sin, 1997). Sophora Radix also keeps cold character and has been used to treat skin diseases such as pruritus or scabies (Sin, 1997). On the other hand, Atractylodis Rhizoma keeps warm character and has been used to prevent the clear heat and dry dampness medicinal-induced side effect or stomach ache as well as to treat limbs and the knee joint pain (Sin, 1997). Shark cartilage has been often used to treat for joint problems. In addition, Jeong et al. (2012) have reported that BT inhibited RA through negative regulation of IL-32 pathways.

Inflammation is involved in increasing number of diseases necessitating the development of new, effective, and safe treatments. Non-steroidal anti-inflammatory drugs (NSAIDs) have been helpful in inflammatory diseases through the inhibition of cyclooxygenase- 2 and inflammatory cytokines (Conti et al., 2013). However, NSAIDs are accomplished with adverse effects such as cardiovascular, renal, and gastrointestinal toxicity (Cavagna et al., 2013; Lindberg 2013). The traditional medicine therapies are generally considered to be safe and efficacy by general population (Guo and Liu 2013). Therefore, we examined whether BT can regulate the inflammatory cytokine production signaling pathway in phorbol 12-myristate 13-acetate (PMA) and calcium ionophore A23187 (PMACI)-stimulated human mast cells (HMC)-1.

\section{MATERIALS AND METHODS}

\section{Materials}

PMA, A23187, dimethyl sulfoxide (DMSO), 3-(4, 5-dimethylthiazol-2-yl)-2, 5-diphenyltetrazolium bromide (MTT), hesperidin, glycyrrhizin, dexamethasone, and other reagent were purchased from Sigma (St. Louis, MO, USA). Iacove's midified Dulbecco's medium (IMDM) and fetal bovine serum (FBS) were purchased from Gibco BRL (Grand Island, NY, USA). Anti-human TSLP, IL-1 $\beta$, IL-6, IL-8, and TNF- $\alpha$ biotinylated anti-human TSLP, IL-1 $\beta$, IL-6, IL-8, and TNF- $\alpha$, recombinant human (rh) TSLP, IL-1 $\beta$, IL-6, IL-8, and TNF- $\alpha$ were purchased from Pharmingen (San Diego, CA, USA). Antibodies (Abs) for caspase-1, ERK, phosphorylated (p) extracellular signal-regulated kinase (ERK), p38, pp38, c-Jun $\mathrm{N}$-terminal kinase (JNK), pJNK, NF- $\mathrm{B}$, I $\mathrm{BB} \alpha$, and $\beta$-actin were obtained from Santa Cruz Biotechnology (Santa Cruz, CA, USA). The caspase assay kit was supplied by R\&D Systems Inc. (Minneapolis, MN, USA).

\section{Cell culture}

The HMC-1 cells have been established from the peripheral blood of a patient with mast cell leukemia (Butterfield et al., 1988). The HMC-1 was grown in IMDM supplemented with $100 \mathrm{U} / \mathrm{ml}$ penicillin, $100 \mathrm{mg} / \mathrm{ml}$ streptomycin, and $10 \%$ heat inactivated $\mathrm{FBS}$ at $37^{\circ} \mathrm{C}, 5 \% \mathrm{CO}_{2}$ and $95 \%$ humidity.

\section{Preparation of BT}

BT is composed of shark cartilage (24 g), Atractylodis Rhizoma (Atractylodes lancea DC, 8 g), Phellodendri Cortex (Phellodendron amurense Ruprecht, $8 \mathrm{~g}$ ), and Sophora Radix (Sophora flavescens Solander ex Aiton, 8 g). BT (voucher No 201101) was provided from TeunTeunMadi Korean medical clinic (Seoul, Republic of Korea) and identified by Korean Medical Doctors Woo-Moon Sim, Moo-Chang Sul, Min-Cheol Kim, Chang-Hee Lee, Dong- Won Kim, Se-Hun Lee, Ho-Cheol Lee, Jong-Min Ryu, Bong-Soo Nam, Jong-Ok Kim, Seong-Oh Moon, Hyeon-Lok Jang, Young-Seok Kim, Ihn Lee, Jin-Young Yang, Kyu-SunHwang, Chang-Sun Chun, Hyeon-Seok Jeong. An extract of BT was prepared by decocting the dried prescription of herbs with boiling distilled water $(48 \mathrm{~g} / \mathrm{l})$. The product was filtered, lyophilized and kept at $4^{\circ} \mathrm{C}$. The yield of dried product from starting materials was about $35.6 \%$. The samples were dissolved in distilled water and then filtered through $0.22 \mu \mathrm{m}$ syringe filter.

\section{ELISA}

Secreted TSLP, IL-1 $\beta$, IL-6, IL-8, and TNF- $\alpha$ in culture supernatants were measured according to the manufacturer's specification (Pharmingen, San Diego, CA, USA).

\section{MTT assay}

HMC-1 cell aliquots $\left(3 \times 10^{5}\right.$ cells/ml $)$ were cultured in microplate wells for $8 \mathrm{~h}$ after treatment by BT and incubated with $20 \mu \mathrm{l}$ of an MTT solution $(5 \mathrm{mg} / \mathrm{ml})$ for additional $4 \mathrm{~h}$ at $37^{\circ} \mathrm{C}$ under $5 \% \mathrm{CO}_{2}$ and $95 \%$ air. Consecutively, $250 \mu \mathrm{l}$ of DMSO was added to extract the MTT formazan and the absorbance of each well at $540 \mathrm{~nm}$ was read by an automatic microplate reader.

\section{RNA isolation and RT-PCR}

Total RNA was isolated from HMC-1 according to the manufacturer's specifications using an easy-BLUE RNA extraction kit (iNtRON Biotech, Korea). Total RNA $(2.0 \mu \mathrm{g})$ was heated at $65^{\circ} \mathrm{C}$ for $10 \mathrm{~min}$ and then chilled on ice. Each sample was reverse-transcribed to cDNA for $90 \mathrm{~min}$ at $37^{\circ} \mathrm{C}$ using a cDNA synthesis kit. RT-PCR was carried out with $1 \mu \mathrm{l}$ of a cDNA mixture, in $20 \mu \mathrm{l}$ final volume with $2.5 \mathrm{mM} \mathrm{MgCl}_{2}$, $200 \mathrm{mM}$ dNTPs, $25 \mathrm{pM}$ cytokine primers, and $2.5 \mathrm{U}$ of TaqDNA polymerase in the reaction buffer $(50 \mathrm{mM} \mathrm{KCl}, 10$ $\mathrm{mM}$ Tris- $\mathrm{HCl}, \mathrm{pH} 9$, and $0.1 \%$ Triton $\mathrm{X}-100)$. PCR was performed with the following primers for human TSLP (5' TAT GAG TGG GAC CAA AAG TAC CG 3' and 5' GGG ATT GAA GGT TAG GCT CTG G 3'); human IL-1 $\beta$ (5' CCG GAT CCA TGG CAC CTG TAC GAT CA 3'; 5' GGG GTA CCT TAG GAA GAC ACA AAT TG 3'); human IL-6 (5' GAT GGATGC TTC CAATCT GGAT 3'; 5' AGT TCT CCATAG AGA ACA ACA TA 3'); human IL-8 (5' CGA TGT CAG TGC ATA AAG ACA 3'; 5' TGA ATT CTC AGC CCT CTT CAA AAA 3'); human TNF- $\alpha$ (5' CAC CAG CTG GTT ATC TCT CAG CTC 3'; 5' CGG GAC GTG GAG CTG GCC GAG GAG 3'); GAPDH (5' CAA AAG GGT CAT CAT CTC TG 3'; 5' CCT GCT TCA CCA CCT TCT TG 3'). The annealing temperature was $62^{\circ} \mathrm{C}$ for TSLP, $50^{\circ} \mathrm{C}$ for IL- $1 \beta, 56^{\circ} \mathrm{C}$ for IL-6, and $60^{\circ} \mathrm{C}$ for IL-8, TNF- $\alpha$, and GAPDH. Products were electrophoresed on a $1.5 \%$ agarose gel and visualized by staining with ethidium bromide.

\section{Western blot analysis}

For analysis of protein level of indicated proteins in the text, stimulated cells were rinsed twice with ice-cold phosphate buffered saline (PBS) and then lysed in ice-cold lysis buffer (PBS containing $0.1 \%$ SDS, $1 \%$ triton and $1 \%$ deoxycholate). Cell lysates were separated through electrophoresis, the protein was transferred to nylon membranes by electrophoretic transfer. The membranes were blocked in 5\% skim milk for $2 \mathrm{~h}$, rinsed and incubated overnight at $4{ }^{\circ} \mathrm{C}$ with primary Abs (Santa Cruz Biotechnology, Santa Cruz, CA). After three washes in PBS containing $0.05 \%$ Tween-20 (PBST), the membranes were incubated for $1 \mathrm{~h}$ with horse radish peroxidase-conjugated secondary Abs. After three washes in PBST, the protein bands were visualized by an enhanced chemiluminescence assay following the manufacturer's instructions.

\section{Caspase-1 activity}

The enzymatic activity of caspase-1 was assayed using a caspase-1 colorimetric assay kit according to the manufacturer's 
A

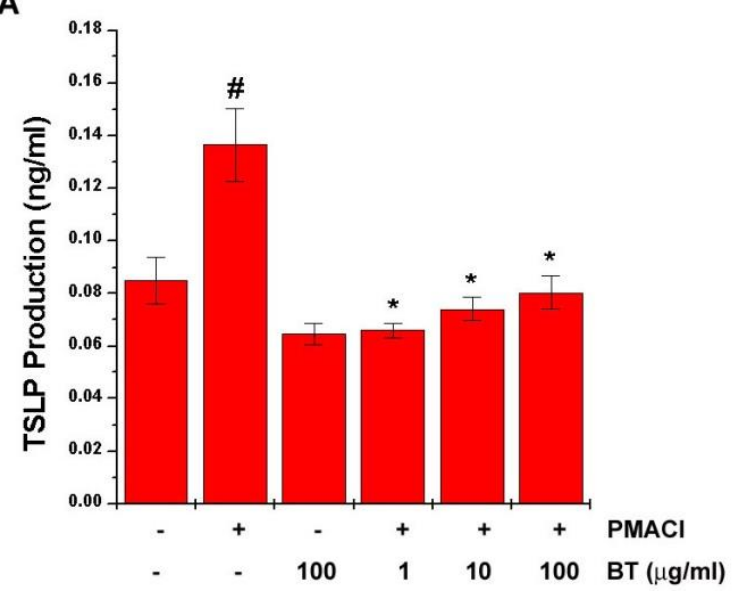

C

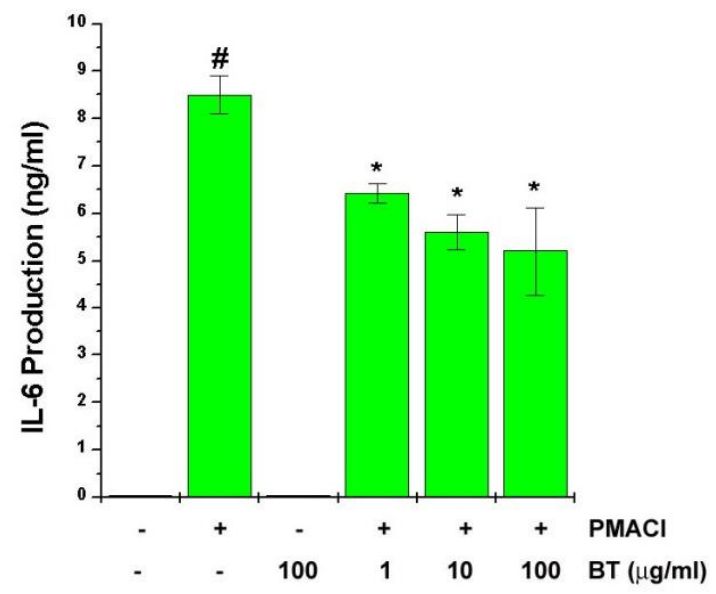

$\mathbf{E}$

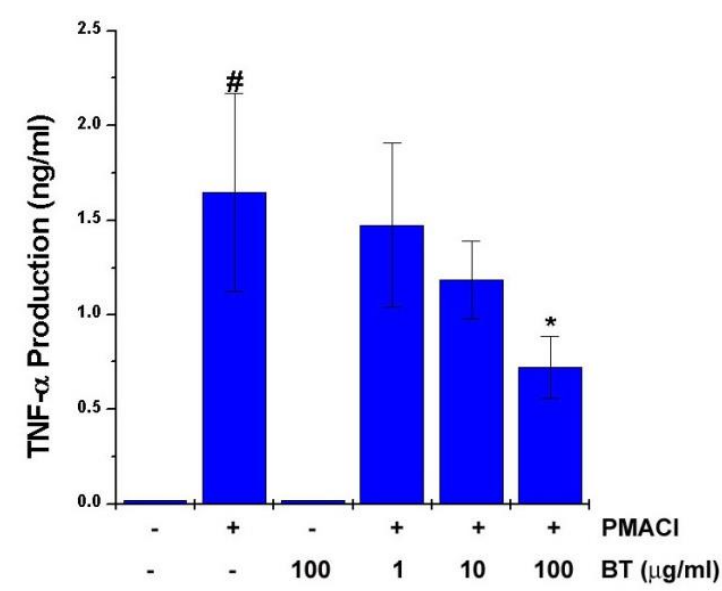

B

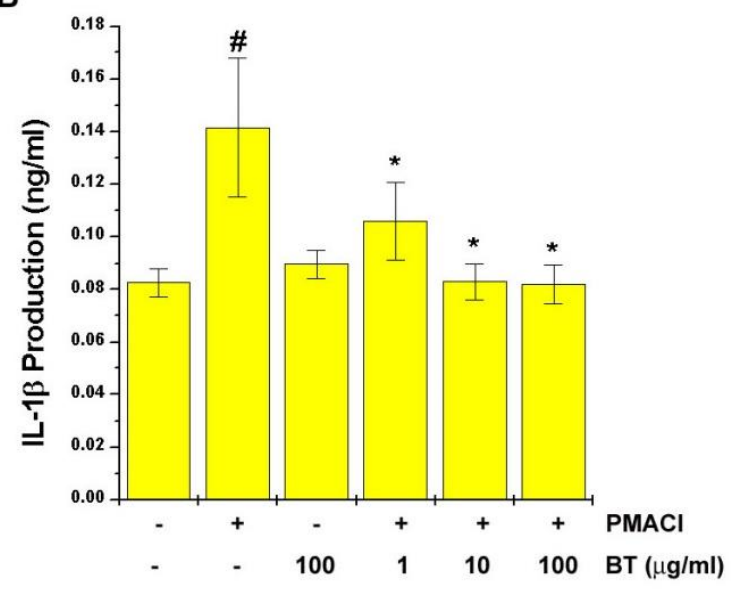

D

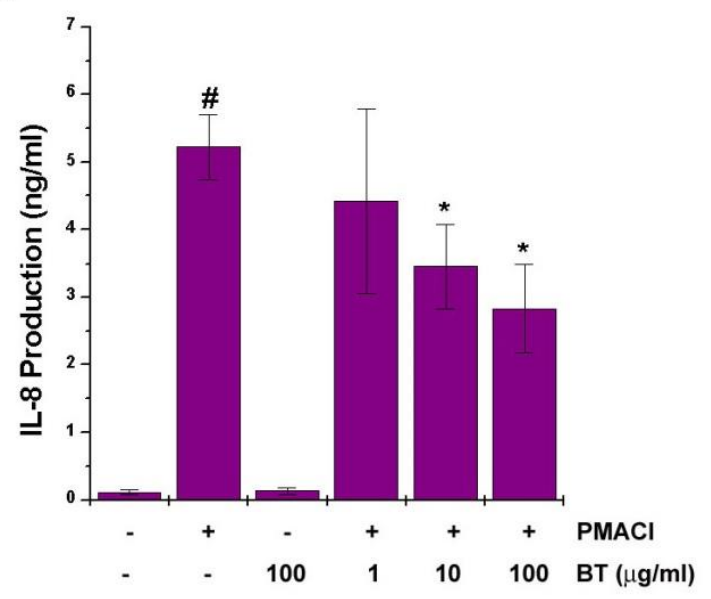

$\mathbf{F}$

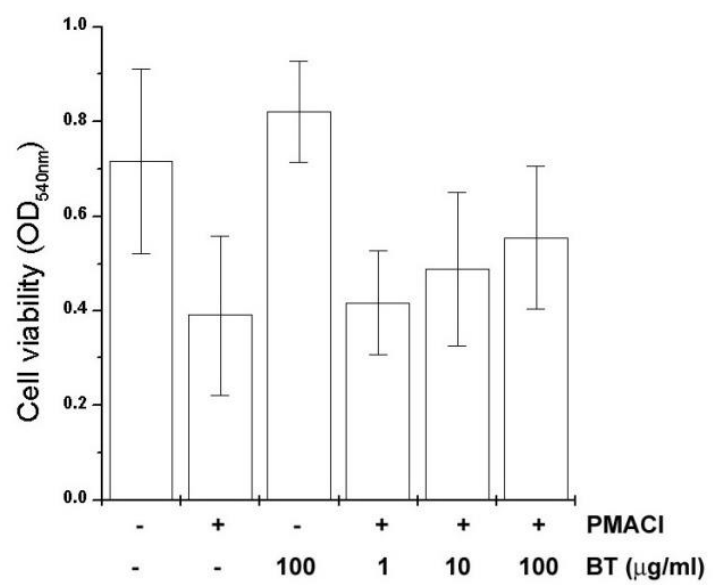

Fig. 1. Effect of BT on inflammatory cytokine secretion and cell viability in HMC-1 cells. The cells were pretreated with various concentrations of BT $(1,10$, and $100 \mu \mathrm{g} / \mathrm{ml})$ for $2 \mathrm{~h}$ prior to PMACI stimulation for $8 \mathrm{~h}$. (A-E) Secreted cytokine levels in culture supernatants of cells were measured by the ELISA method. (F) Cell viability was evaluated by an MTT assay. Data represent mean \pm S.D. of three independent experiments. ${ }^{\#} p<0.05$ : significantly different from unstimulated cells. ${ }^{*} p<0.05$ : significantly different from the PMACI-stimulated cells. PMACI, PMA plus A23187; BT, BaekJeol-Tang.

protocol. The lysed cells were centrifuged at $15,000 \times \mathrm{g}$ for 5 min. The protein supernatant was incubated with $50 \mu$ reaction buffer and $5 \mu \mathrm{l}$ caspase substrate (WEHD-p-nitroaniline) at $37^{\circ} \mathrm{C}$ for $2 \mathrm{~h}$. The absorbance was measured was measured using a plate reader at a wavelength of $405 \mathrm{~nm}$. Equal amounts of the total protein from each lysate were quantified using a bicinchoninic acid protein quantification kit (Pierce, Rockford, IL, USA). 


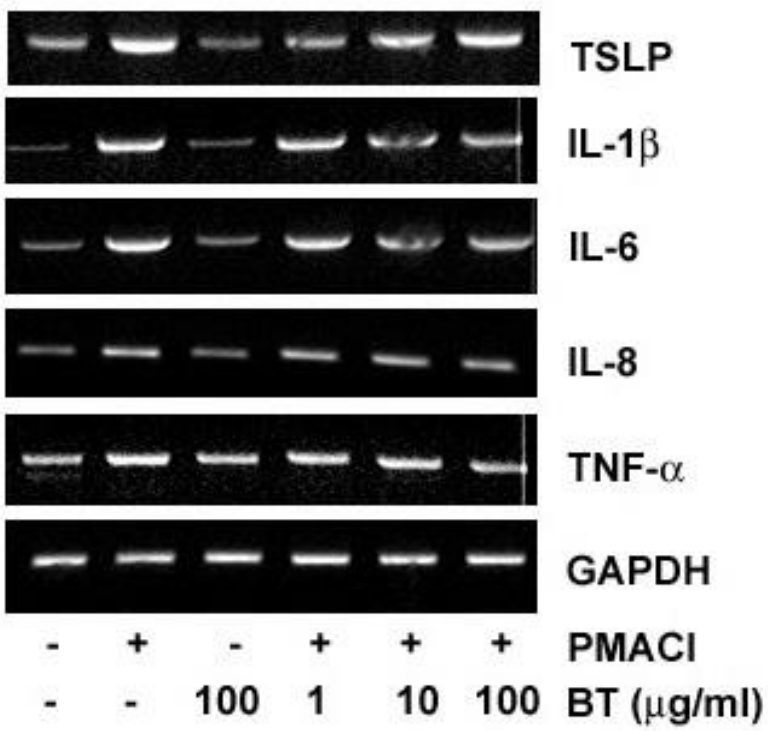

Fig. 2. Effect of BT in inflammatory cytokine mRNA expression. The cells were pretreated with various concentrations of BT $(1,10$, and 100 $\mu \mathrm{g} / \mathrm{ml}$ ) for $2 \mathrm{~h}$ prior to PMACI stimulation for $6 \mathrm{~h}$. The total RNA was assayed by an RT-PCR analysis. Results are representative of three independent experiments. PMACI, PMA plus A23187; BT, BaekJeol-Tang

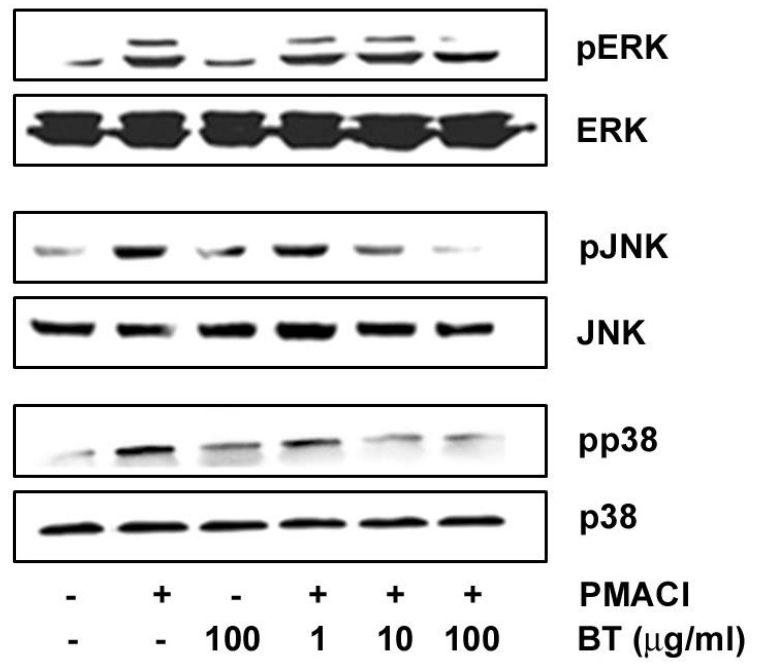

Fig. 3. Effect of BT on MAPKs phosphorylation in HMC-1 cells. The cells were pretreated with of BT $(1,10$, and $100 \mu \mathrm{g} / \mathrm{ml})$ for $2 \mathrm{~h}$ prior to PMACI stimulation for $2 \mathrm{~h}$. The phosphorylated MAPKs levels were assayed by Western blot analysis. Results are representative of three independent experiments. PMACI, PMA plus A23187; BT, BaekJeol-Tang.

\section{Statistical analysis}

Results were expressed as the mean \pm standard deviation (S.D) of independent experiments. All statistical analyses were performed by one-way analysis of variance with Tukey post hoc test to express the difference between groups using SPSS v12.00 statistical analysis software (SPSS Inc., IL, USA). A value of $p<0.05$ was considered to indicate statistical significance.

\section{RESULTS}

Inhibitory effect of BT on inflammatory cytokines secretion and mRNA expression in HMC-1 cells
In the nuclear extract

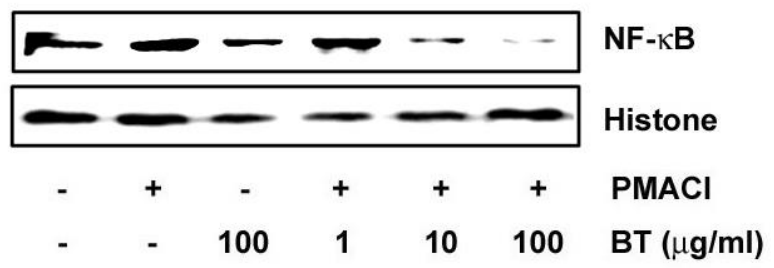

\section{In the cytoplasmic extract}

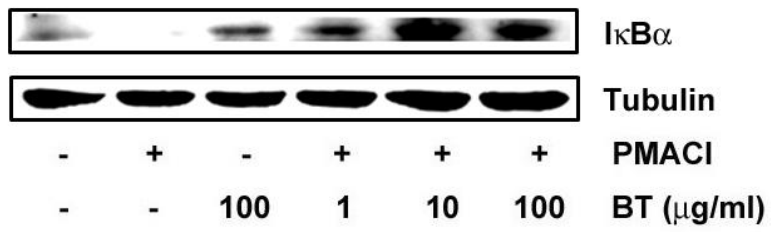

Fig. 4. Effect of $\mathrm{BT}$ on $\mathrm{NF}-\kappa \mathrm{B}$ activation and $\mathrm{I} \kappa \mathrm{B} \alpha$ degradation in HMC-1 cells. The cells were pretreated with of BT $(1,10$, and 100 $\mu \mathrm{g} / \mathrm{ml}$ ) for $2 \mathrm{~h}$ prior to PMACI stimulation for $2 \mathrm{~h}$. Nuclear protein and cytoplasmic protein were prepared and analyzed for $\mathrm{NF}-\kappa \mathrm{B}$ and $\mathrm{I} \kappa \mathrm{B} \alpha$ by Western blotting as described in the experimental procedures. Results are representative of three independent experiments. PMACI, PMA plus A23187; BT, BaekJeol-Tang.

We examined the regulatory effect of BT on the production of TSLP, IL- $1 \beta$, IL-6, IL- 8 , and TNF- $\alpha$. PMACI significantly increased cytokine production compared with the media control (Fig. 1A-E). TSLP, IL-1 $\beta$, IL-6, IL-8, and TNF- $\alpha$ increased by PMACI were significantly inhibited by BT (Fig. 1A-E, $p<$ $0.05)$. Using the pretreated HMC-1 cells described above, we also performed a RT-PCR analysis for TSLP, IL-1 $\beta$, IL-6, IL-8, and TNF- $\alpha$ to determine whether BT modulated PMACI-induced cytokines mRNA expressions. The mRNA expressions of TSLP, IL-1 $\beta$, IL-6, IL-8, and TNF- $\alpha$ were up-regulated by PMACI stimulation but the up-regulated cytokine mRNA expressions were decreased with BT (Fig. 2). We examined cell viability using a MTT assay. BT had no effect on cell viability (Fig. 1F).

Inhibitory effect of BT on MAPKs phosphorylation in HMC-1 cells

To determine the regulatory effect of BT on the MAPKs activation induced by PMACI, Western blot analysis for phosphorylated ERK, JNK, and p38 MAPKs was performed. The result showed that MAPKs phosphorylation was increased by PMACI, but the treatment of BT suppressed the phosphorylation of ERK, JNK, and p38 in PMACI-stimulated cells (Fig. 3).

Inhibitory effect of BT on NF-кB activation and IкB degradation in HMC-1 cells

The expression of inflammatory cytokines was regulated by the transcription factor, NF- $\kappa B$ (Song et al., 2012). Therefore, we examined the effect of BT on PMACI-induced NF- $\mathrm{BB}$ activation. In the nuclear, the increased NF- $\kappa B$ level by PMACI was reduced by the treatment with BT (Fig. 4). To examine whether the inhibitory action of BT was due to its effects on $\mathrm{I} \kappa \mathrm{B}$ degradation, we investigated the cytoplasmic levels of $\mathrm{I} \kappa \mathrm{B} \alpha$ protein with a Western blot analysis. The degradation of $\mathrm{I} \kappa \mathrm{B} \alpha$ in the cytoplasm was inhibited by the treatment with BT (Fig. 4).

Inhibitory effect of BT on caspase-1 activation in HMC-1 cells

2013 / Volume 3 / Issue 2 / e18 
A

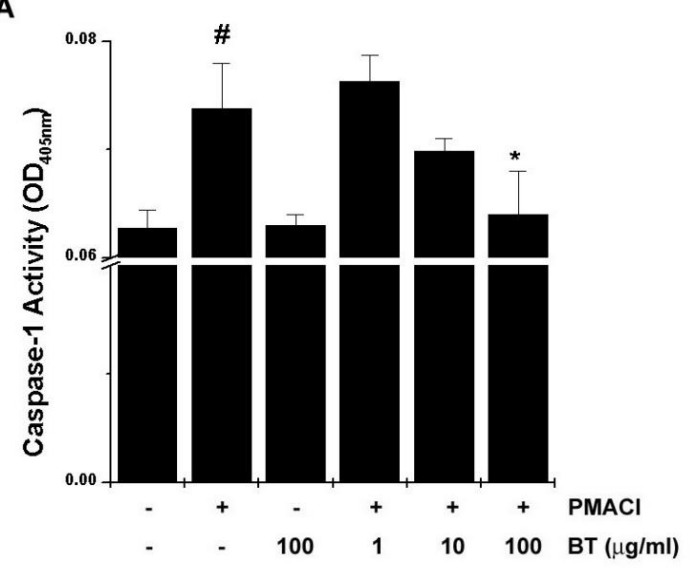

B

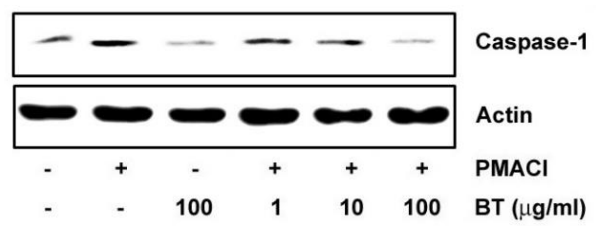

Fig. 5. Effect of BT on caspase-1 activation in HMC-1 cells. The cells were pretreated with various concentrations of BT $(1,10$, and 100 $\mu \mathrm{g} / \mathrm{ml}$ ) for $2 \mathrm{~h}$ prior to PMACI stimulation for $2 \mathrm{~h}$. (A) The enzymatic activity of caspase- 1 was tested by a caspase- 1 colorimetric assay. Data represent mean \pm S.D. of three independent experiments. (B) The levels of caspase-1 were assayed by Western blot analysis. Results are representative of three independent experiments. ${ }^{\# p}<0.05$ : significantly different from unstimulated cells. ${ }^{*} p<0.05$ : significantly different from the PMACI-stimulated cells. PMACI, PMA plus A23187; BT, BaekJeol-Tang.

Caspase-1 plays a central role in developing pro-inflammatory cytokines (Jeong et al., 2010). To evaluate the regulatory effect of BT on the caspase-1 activation induced by PMACI, we measured the caspase-1 activity using a caspase-1 assay kit. Caspase-1 activity was significantly decreased with BT treatment (Fig. 5A). Western blot analysis for active caspase-1 was also performed. Once again, caspase-1 activation was significantly decreased with BT treatment (Fig. 5B, $p<0.05$ ).

\section{DISCUSSION}

Mast cells play a role in the pathogenesis of arthritic diseases and infiltrate into synovium in patients with RA and OA. Tryptase, histamine, and inflammatory cytokines released from mast cells increase the inflammatory process and destroy the joint via stimulation of various cell types including T-cells, B cells, and macrophages (Nakano et al., 2007; Suurmond et al., 2011). The levels of cytokines in the synovial fluid of patients with OA are in some cases as high as in patients with RA, and inflammatory and destructive responses have been described in OA and RA cartilage (Bondeson et al. 2010; Simopoulou et al. 2010; Sverdrup et al. 2010). IL-17 expression by mast cells leading to inflammation, breakdown cartilage, and bone erosion via the production of other inflammatory factors such as IL-1, IL-6, TNF- $\alpha$, and matrix metalloproteinases (Suurmond et al., 2011). TSLP levels were increased in synovial fluid of derived from patients with arthritis. IL-32-induced TSLP induced the macrophage differentiation (Jeong et al., 2012). In addition, TSLP expression in RA- and OA-derived synovial fibroblasts was up-regulated by TNF- $\alpha$. The anti-TSLP neutralizing TANG / www.e-tang.org antibody ameliorated a TNF- $\alpha$-dependent experimental arthritis induced by anti-type II collagen antibody in mice (Koyama et al., 2007). IL-8 is produced in arthritic joints by activated synovial cells and infiltrating macrophages and considered to be potent catabolic factors in arthritic joints (Rasheed et al., 2011). In arthritic joints, IL-8 induces a massive accumulation of neutrophils, which produce neutrophil elastase, leading to cartilage destruction (Matsukawa et al., 1995). These inflammatory cytokine expressions are dependent on MAPKs and NF- $\kappa \mathrm{B}$ signal transduction. Activated NF- $\kappa \mathrm{B}$ regulates the expression of many cytokines and chemokines, adhesion molecules, inflammatory mediators, and several matrix degrading enzymes (Marcu et al., 2010; Jeong et al., 2010). $\mathrm{NF}-\kappa \mathrm{B}$ activation was mediated by caspase-1 activation (Lamkanfi et al., 2006). Caspase recruitment domain (CARD) of procaspase-1 can mediate NF- $\mathrm{KB}$ activation by receptor-interacting protein-2 through a CARD-CARD interaction (Kersse et al., 2011). BT has been used to treat inflammatory diseases, especially arthritis in traditional Korean medicine. Thus, we examined the effect of BT on the productions of inflammatory cytokines in mast cells. BT inhibited the production of inflammatory cytokines and activation of MAPKs, NF- $\kappa \mathrm{B}$, and caspase-1 in activated mast cells. Therefore, we suggested that these anti-inflammatory effects by BT were dependent on the regulation of MAPKs/NF- $\kappa \mathrm{B} /$ caspase- 1 signaling pathways.

In conclusion, these reports imply that BT reduced the inflammatory cytokine expression through the blockade of signaling cascade of the MAPKs, NF- $\mathrm{KB}$, and caspase-1 activation in mast cells. For that reason, we suggest that BT may be an effective therapeutic agent for RA and OA treatment.

Taken together, we think that traditional Korean medicine can develop when it is studied on the basis of traditional Korean medicine theory. Herbs used in Korean medicine have their own identities and it is difficult to explain their natures in terms of its constituent compounds. Their effects must be considered after total and final reaction when administrated to humans. We hope this report can contribute to the development of current Korean medicine in substantial ways.

\section{ACKNOWLEDGEMENTS}

This research was supported by Kyung Hee University.

\section{CONFLICT OF INTEREST}

The authors declare that there are no conflicts of interest.

\section{REFERENCES}

Bridges AJ, Malone DG, Jicinsky J, Chen M, Ory P, Engber W, Graziano FM. Human synovial mast cell involvement in rheumatoid arthritis and osteoarthritis. Relationship to disease type, clinical activity, and antirheumatic therapy. Arthritis Rheum. 1991;34:1116-1124.

Buckley MG, Gallagher PJ, Walls AF. Mast cell subpopulations in the synovial tissue of patients with osteoarthritis: selective increase in numbers of tryptase-positive, chymase-negative mast cells. J Pathol. 1998;186:67-74.

Cauli A, Pitzalis C, Yanni G, Awad M, Panayi GS. CD1 expression in psoriatic and rheumatoid arthritis. Rheumatology

2013 / Volume 3 / Issue 2 / e18 


\section{(Oxford). 2000;39:666-673}

Cavagna L, Caporali R, Trifiro' G, Arcoraci V, Rossi S, Montecucco C. Overuse of prescription and otc non-steroidal anti-inflammatory drugs in patients with rheumatoid arthritis and osteoarthritis. Int $\mathbf{J}$ Immunopathol Pharmacol. 2013;26:279-281.

Ceponis A, Konttinen YT, Takagi M, Xu JW, Sorsa T, Matucci-Cerinic M, Santavirta S, Bankl HC, Valent P. Expression of stem cell factor (SCF) and SCF receptor (c-kit) in synovial membrane in arthritis: correlation with synovial mast cell hyperplasia and inflammation. J Rheumatol. 1998;25:2304-2314.

Clockaerts S, Bastiaansen-Jenniskens Y, Feijt C, Verhaar J, Somville J, De Clerck L, Van Osch GJ. Peroxisome proliferator activated receptor alpha activation decreases inflammatory and destructive responses in osteoarthritic cartilage. Osteoarthritis Cartilage. 2011;9:895-902.

Conti P, Varvara G, Murmura G, Tete S, Sabatino G, Saggini A, Rosati M, Toniato E, Caraffa A, Antinolfi P, Pandolfi F, Potalivo G, Galzio R, Theoharides TC. Comparison of beneficial actions of non-steroidal anti-inflammatory drugs to flavonoids. J Biol Regul Homeost Agents. 2013;27:1-7.

Damsgaard TE, Sorensen FB, Herlin T, Schiotz PO. Stereological quantification of mast cells in human synovium. APMIS. 1999;107:311-317.

de Lange-Brokaar BJ, Ioan-Facsinay A, van Osch GJ, Zuurmond AM, Schoones J, Toes RE, Huizinga TW, Kloppenburg M. Synovial inflammation, immune cells and their cytokines in osteoarthritis: a review. Osteoarthritis Cartilage. 2012;20:1484-1499.

Dean G, Hoyland JA, Denton J, Donn RP, Freemont AJ. Mast cells in the synovium and synovial fluid in osteoarthritis. Br J Rheumatol. 1993;32:671-675.

Deleuran B, Lemche P, Kristensen M, Chu CQ, Field M, Jensen J, Matsushima K, Stengaard-Pedersen K. Localisation of interleukin 8 in the synovial membrane, cartilageepannus junction and chondrocytes in rheumatoid arthritis. Scand J Rheumatol. 1994;23:2-7.

Doss F, Menard J, Hauschild M, Kreutzer HJ, Mittlmeier T, Muller-Steinhardt M, Müller B. Elevated IL-6 levels in the synovial fluid of osteoarthritis patients stem from plasma cells. Scand J Rheumatol. 2007;36:136-139.

Guo H, Liu MP. Mechanism of traditional Chinese medicine in the treatment of allergic rhinitis. Chin Med J (Engl). $2013 ; 126: 756-760$

Heo J. Dongui Bogam. (Seoul, Republic of Korea: Bubin publishers co.), 1999.

Jeong HJ, Choi IY, Kim MH, Kim HM, Moon PD, Hong JW, Kim SH. Chungsim-Yeunja-Tang decreases the inflammatory response in peripheral blood mononuclear cells from patients with cerebral infarction through an NF- $\kappa \mathrm{B}$ dependent mechanism. J Neuroinflammation. 2010;7:85.

Jeong HJ, Nam SY, Oh HA, Han NR, Kim YS, Moon PD, Shin SY, Kim MH, Kim HM. Interleukin-32-induced thymic stromal lymphopoietin plays a critical role in macrophage differentiation through the activation of caspase-1 in vitro. Arthritis Res Ther. 2012;14:R259.

Kersse K, Lamkanfi M, Bertrand MJ, Vanden Berghe T, Vandenabeele P. Interaction patches of procaspase-1 caspase recruitment domains (CARDs) are differently involved in procaspase-1 activation and receptor-interacting protein 2 (RIP2)-dependent nuclear factor $\mathrm{\kappa B}$ signaling. J Biol Chem. 2011;286:35874-35882.

Koyama K, Ozawa T, Hatsushika K, Ando T, Takano S, Wako M, Suenaga F, Ohnuma Y, Ohba T, Katoh R, Sugiyama H, Hamada Y, Ogawa H, Okumura K, Nakao A. A possible role for TSLP in inflammatory arthritis. Biochem Biophys Res Commun. 2007;357:99-104.

Lamkanfi M, Declercq W, Vanden Berghe T, Vandenabeele P. Caspases leave the beaten track: caspase-mediated activation of NF-kappaB. J Cell Biol. 2006;173:165-171.

Lindberg M. Use of NSAIDs in rheumatoid arthritis should be limited. Ugeskr Laeger. 2013;175:1039-1041.

Marcu KB, Otero M, Olivotto E, Borzi RM, Goldring MB. NF-kappaB signaling: multiple angles to target OA. Curr Drug Targets. 2010;11:599-613.

Matsukawa A, Yoshimura T, Maeda T, Ohkawara S, Takagi K, Yoshinaga M. Neutrophil accumulation and activation by homologous IL-8 in rabbits. IL-8 induces destruction of cartilage and production of IL-1 and IL-1 receptor antagonist in vivo. J Immunol. 1995;154:5418-5425.

Melchiorri C, Meliconi R, Frizziero L, Silvestri T, Pulsatelli L, Mazzetti I, Borzì RM, Uguccioni M, Facchini A. Enhanced and coordinated in vivo expression of inflammatory cytokines and nitric oxide synthase by chondrocytes from patients with osteoarthritis. Arthritis Rheum. 1998;41:2165-2174.

Moon PD, Kim HM. Thymic stromal lymphopoietin is expressed and produced by caspase- $1 / \mathrm{NF}-\mathrm{\kappa B}$ pathway in mast cells. Cytokine. 2011;54:239-243.

Nakano S, Mishiro T, Takahara S, Yokoi H, Hamada D, Yukata K, Takata Y, Goto T, Egawa H, Yasuoka S, Furouchi H, Hirasaka K, Nikawa T, Yasui N. Distinct expression of mast cell tryptase and protease activated receptor- 2 in synovia of rheumatoid arthritis and osteoarthritis. Clin Rheumatol. 2007;26:1284-1292.

Rasheed Z, Akhtar N, Haqqi TM. Advanced glycation end products induce the expression of interleukin-6 and interleukin-8 by receptor for advanced glycation end product-mediated activation of mitogen-activated protein kinases and nuclear factor- $\mathrm{\kappa B}$ in human osteoarthritis chondrocytes. Rheumatology (Oxford). 2011;50:838-851.

Saha N, Moldovan F, Tardif G, Pelletier JP, Cloutier JM, Martel-Pelletier J. Interleukin-1beta-converting enzyme/caspase-1 in human osteoarthritic tissues: localization and role in the maturation of interleukin-1beta and interleukin-18. Arthritis Rheum. 1999;42:1577-1587.

Schett G, Firestein GS. Mr Outside and Mr Inside: classic and alternative views on the pathogenesis of rheumatoid arthritis. Ann Rheum Dis. 2010;69:787-789.

2013 / Volume 3 / Issue 2 / e18 
Sin MG. Clinical traditional herbalogy. (Seoul, Republic of Korea: Yeongrim publishers co.), pp. 405-406, 394-395, 180-181, 1997.

Song YH, Nam SY, Choi Y, Kim JY, Kim YS, Jeong HJ. Socioeconomic impact of traditional Korean medicine, Pyeongwee-San (KMP6) as an anti-allergic inflammatory drug. TANG. 2012;2:e29.

Suurmond J, Dorjée AL, Boon MR, Knol EF, Huizinga TW, Toes RE, Schuerwegh AJ. Mast cells are the main interleukin 17-positive cells in anticitrullinated protein antibody-positive and -negative rheumatoid arthritis and osteoarthritis synovium.
Arthritis Res Ther. 2011;13:R150.

van Eekeren IC, Clockaerts S, Bastiaansen-Jenniskens YM, Lubberts E, Verhaar JA, van Osch GJ, Bierma-Zeinstra SM. Fibrates as therapy for osteoarthritis and rheumatoid arthritis? A systematic review. Ther Adv Musculoskelet Dis. 2013;5:33-44.

Zhang K, Shan L, Rahman MS, Unruh H, Halayko AJ, Gounni AS. Constitutive and inducible thymic stromal lymphopoietin expression in human airway smooth muscle cells: role in chronic obstructive pulmonary disease. Am J Physiol Lung Cell Mol Physiol. 2007;293:L375-L382. 